\title{
Normal Values of Lower Limb Nerve Conduction in Kuwait
}

\section{Part II}

\author{
Dia Shehaba Mohamed A.A. Moussa ${ }^{b}$ \\ Departments of a Medicine and ${ }^{\mathrm{b}}$ Community Medicine, Faculty of Medicine, \\ Kuwait University, Kuwait
}

\section{Key Words}

Electrodiagnosis - Nerve conduction .

Normal values $\cdot$ Kuwait

\begin{abstract}
Objectives: To establish the normal electrophysiological values of the common lower limb nerves and to study the relationship of conduction velocity (CV) of the lower limb nerves to height and age in healthy adult subjects. Methods: Nerve conduction investigations were performed on the lower limbs of 51 screened healthy volunteers using standard electrophysiological techniques. $\boldsymbol{R e}$ sults: Fifty-one subjects (21 males and 30 females) participated in the study. The mean $( \pm \mathrm{SD})$ ages of the subjects were $38( \pm 8.82)$ and 36 ( \pm 8.58 ) years for males and females, respectively. The tibial motor nerve showed a mean ( \pm SD) CV of 46.1 ( \pm 3.3 ) m/s, distal latency (DL) $4.4( \pm 0.8) \mathrm{ms}$, and amplitude $8.8( \pm 3.4) \mathrm{mV}$ for males. For females, the
\end{abstract}

\begin{tabular}{ll}
\hline KARGER & (1) 1999 S. Karger AG, Basel \\
Fax +4161306 1234 $34-7571 / 99 / 0082-0134 \$ 17.50 / 0$ \\
$\begin{array}{l}\text { E-Mail karger@karger.ch } \\
\text { www.karger.com }\end{array}$ & $\begin{array}{l}\text { Accessible online at: } \\
\text { http://BioMedNet.com/karger }\end{array}$
\end{tabular}

results were CV $47.8( \pm 3.4) \mathrm{m} / \mathrm{s}, \mathrm{DL} 3.9$ $( \pm 0.85) \mathrm{ms}$ and amplitude $12.0( \pm 3.4) \mathrm{mV}$. Peroneal motor parameters were CV 47.1 ( \pm 3.3 ) m/s, DL 3.9 ( \pm 0.53 ) ms, amplitude 5.6 $( \pm 2.2) \mathrm{mV}$ for males and $49.3( \pm 2.3) \mathrm{m} / \mathrm{s}, 4.0$ $( \pm 0.56) \mathrm{ms}, 6.0( \pm 2.2) \mathrm{mV}$ for females, respectively. The sural sensory nerve parameters were CV $48.7 \pm 6.0 \mathrm{~m} / \mathrm{s}$, DL 2.9 ( \pm 0.3 ) ms, amplitude $18.9( \pm 3.3) \mu \mathrm{V}$ for males and $51.5( \pm 4.9) \mathrm{m} / \mathrm{s}, 2.7( \pm 0.24) \mathrm{ms}$ and 21.6 ( \pm 6.3$) \mu \mathrm{V}$ for females. Most $\mathrm{CV}$ values were significantly correlated with height, and there was a significant difference between males and females. However, after adjustment for height by the linear regression method, all significant gender differences disappeared. Conclusion: This study established the normative conduction parameters of the commonly tested nerves of the lower limbs for our electromyography laboratory in Kuwait. Gender differences disappeared when the data were adjusted for age and height.
Dr. Dia Shehab, FRCPC

Department of Medicine, Faculty of Medicine PO Box 24923

Safat 13110 (Kuwait)

Fax +965 5338907, E-Mail Diaa@hsc.kuniv.edu.kw 


\section{Introduction}

Every electrophysiological laboratory needs to establish the normal values for its population required in clinical practice to identify abnormal subjects. Nerve conduction studies (NCS) are now routinely performed as an important method to evaluate peripheral nerve injury. There are factors that should be considered upon studying the conduction parameters of the nerves including temperature, age, gender and limb length as these influence nerve conduction parameters [1-10]. In Kuwait, there are no normal values set in our electromyographic (EMG) laboratory. Part I of this study focused on the establishment of normal values of nerve conduction in the upper limbs [11]. The main objectives of this present study are to establish the normal electrophysiological values of the common lower limb nerves by gender, and to study the relationship of conduction velocity of the lower limb nerves to height and age in healthy adult subjects.

\section{Methods}

Fifty-one healthy volunteers were included in the study after giving their consent to participate. All participants were examined to exclude history of systemic or neuromuscular disorders. None of them were on medications that might affect the study results. All subjects had neurological examination for the lower limbs including muscle power testing, muscle stretch reflexes and skin sensation. Height was measured and skin temperature of the lower limbs was recorded at the palm of each subject before the study. The study was carried out at a fixed temperature of $32^{\circ} \mathrm{C}$.

\section{Electrophysiological Method}

A Nicolet Viking II EMG instrument was used with the assistance of one technician. Filters were set at $2 \mathrm{~Hz}$ to $5 \mathrm{kHz}$ for motor studies and $20 \mathrm{~Hz}$ to $2 \mathrm{kHz}$ for sensory studies. Sweep was set a $2 \mathrm{mV}$ per division using supramaximal stimuli to get adequate response. Latencies were measured to the onset of the response, if sensory latency was not clear, then peak latency was

Lower Limb Nerve Conduction Normal Values taken. Amplitudes were measured from negative peak to subsequent positive peak.

Analyses for the following NCS parameters were done: (1) peroneal motor distal latency $(8 \mathrm{~cm})$, amplitude, and below fibular head-to-ankle conduction velocity, (2) tibial motor distal latency, amplitude and knee-to-ankle conduction velocity, (3) sensory sural antidromic calf-to-ankle conduction velocity $(14 \mathrm{~cm})$, latency and amplitude.

\section{Statistical Methods}

Since nerve conduction variables have been shown to have skewed distributions [12], it was decided to utilise the non-parametric, Mann-Whitney U test for evaluating group differences. Raw data were first analysed without adjustment. To adjust for the effects of height and age, we derived a multiple linear regression equation for each NCS parameter as a function of age and height in all subjects. The regression coefficients were then used to adjust the parameters to the mean age of 37 years, and to the mean height of $164 \mathrm{~cm}$ according to the equation:

$$
\begin{aligned}
& \text { Adjusted value }= \\
& \text { raw value }+\beta \mathrm{a}(37-\text { age })+\beta \mathrm{h}(164-\text { height }),
\end{aligned}
$$

where $\beta \mathrm{a}, \beta \mathrm{h}$ are the regression coefficients for age and height, age being the subjects' age and height the measured height. Spearman's correlation was used to assess the extent of association between NCS variables and height.

\section{Results}

Fifty-one subjects (mean age $37 \pm 8.68$ years and range $17-45$ years) participated in the study. There were 21 males (mean age 38 \pm 8.82 years) and 30 females (mean age $36 \pm$ 8.58 years). Descriptive statistics for the motor peroneal, tibial and sensory sural nerves are shown in table 1 for both genders. Comparison of the raw data (unadjusted) showed that females had faster conduction velocities than males. This was statistically significant for sural and peroneal nerves using the MannWhitney U test.

Most conduction velocities were significantly correlated with height in the raw data (Spearman's correlation, $\mathrm{r}_{\mathrm{s}}$ was $-0.399, \mathrm{p}<$ 
Table 1. Nerve conduction parameters of raw data and data adjusted for age and height

\begin{tabular}{|c|c|c|c|c|c|c|}
\hline \multirow[t]{2}{*}{ Parameter } & \multicolumn{3}{|l|}{ Raw data } & \multicolumn{3}{|c|}{ Adjusted for age and height } \\
\hline & $\begin{array}{l}\text { men } \\
(\text { mean } \pm \mathrm{SD})\end{array}$ & $\begin{array}{l}\text { women } \\
(\text { mean } \pm \mathrm{SD})\end{array}$ & $\mathrm{p}$ value & $\begin{array}{l}\text { men } \\
(\text { mean } \pm \mathrm{SD})\end{array}$ & $\begin{array}{l}\text { women } \\
(\text { mean } \pm \mathrm{SD})\end{array}$ & $\mathrm{p}$ value \\
\hline \multicolumn{7}{|c|}{ Conduction velocities, $\mathrm{m} / \mathrm{s}$} \\
\hline Peroneal motor & $47.1 \pm 3.3$ & $49.3 \pm 2.3$ & 0.024 & $48.5 \pm 2.3$ & $48.0 \pm 1.89$ & 0.95 \\
\hline Tibial motor & $46.1 \pm 3.3$ & $47.8 \pm 3.4$ & 0.098 & $46.8 \pm 3.2$ & $47.1 \pm 3.4$ & 0.86 \\
\hline Sural sensory & $48.7 \pm 6.0$ & $51.5 \pm 4.9$ & 0.05 & $50.65 \pm 5.7$ & $50.07 \pm 4.7$ & 0.86 \\
\hline \multicolumn{7}{|l|}{ Latencies, ms } \\
\hline Peroneal motor & $3.9 \pm 0.53$ & $4.0 \pm 0.56$ & 0.796 & $3.8 \pm 0.49$ & $4.0 \pm 6.6$ & 0.51 \\
\hline Tibial motor & $4.4 \pm 0.8$ & $3.9 \pm 0.85$ & 0.091 & $4.3 \pm 0.81$ & $4.1 \pm 0.9$ & 0.27 \\
\hline Sural sensory & $2.9 \pm 0.3$ & $2.7 \pm 0.24$ & 0.015 & $2.8 \pm 0.32$ & $2.8 \pm 0.24$ & 0.73 \\
\hline
\end{tabular}

0.01 for sural conduction velocity; $\mathrm{r}_{\mathrm{s}}=-0.703$, $\mathrm{p}<0.001$ for peroneal conduction velocityknee; $r_{s}=-0.320, p<0.05$ for tibial conduction velocity-knee). After these conduction velocities were adjusted for height and age, all of the statistically significant gender differences disappeared.

\section{Discussion}

This study examined the nerve conduction parameters of commonly studied nerves of the lower limb in healthy subjects. Results were analysed to establish reference data for our population and to determine the relationships with influencing factors, such as gender, age and height. These reference data vary from one population to another. Most of the published normal data of nerve conduction studies are from the Western populations [110, 12, 13]. Kimura [10] reported relatively similar values for the tibial motor nerve including conduction velocity $=48.5 \pm 3.6$, amplitude $=3.8 \pm 1.9$ and latency $=3.9 \pm 1$. For motor peroneal nerve the values were $48.3 \pm 3.9,5.1 \pm 2.3$ and $3.7 \pm 0.86$, respec- tively. For the sensory sural nerve the values were $52.5 \pm 5.6,20.9 \pm 8.0$ and $2.7 \pm 0.3$, respectively. Some studies included the effect of age, gender, temperature and height on the nerve conduction parameters $[3,5,7,8]$. Robinson et al. [8] examined the influence of height and gender on normal nerve conduction studies in men and women and found that most gender differences can be explained by height, while Trojaborg et al. [14] in their study for the sural nerve were unable to confirm the relationship between nerve conduction velocity and height. Soudmand et al. [7] concluded an inverse relationship between height and nerve conduction velocity in the legs.

The results of this study indicate that there is no statistically significant difference in peroneal, tibial and sural nerve conduction velocity between men and women in our population after adjustment for height. Overall, there was a significant correlation between height and nerve conduction velocity. In conclusion, normative conduction parameters of commonly tested peripheral nerves in the lower limb were established for our EMG lab in Kuwait. This can be used for the evaluation 
of peripheral nerve injury. There are no significant differences in motor, peroneal, tibial and sensory nerve conduction velocity between males and females when age and height were fixed.

\section{References}

1 Kimura J: Principles of nerve conduction studies; in Kimura $\mathrm{J}$ (ed): Electrodiagnosis in Diseases of Nerve and Muscle: Principles and Practice, ed 2. Philadelphia, Davis, 1989, pp 78-102.

2 Kimura J: Principles and pitfalls of nerve conduction studies. Ann Neurol 1984;16:415-428.

3 Campbell WW, Ward LC, Swift TR: Nerve conduction velocity varies inversely with height. Muscle Nerve 1981;4:520-523.

4 Halar EM, Delisa JA, Brozovich FV: Peroneal nerve conduction velocity: The importance of temperature correction. Arch Phys Med Rehabil 1981;62:439-443.

5 Falco FJ, Hennessary WJ, Goldberg G, Bradlm RL: Standardized nerve conduction studies in the lower limbs of the healthy elderly. Am J Phys Med Rehabil 1994;73:168174.

\section{Acknowledgement}

We acknowledge with thanks Mr. George Varughese for his secretarial assistance in the preparation of the manuscript.
6 Behse F, Buchthal F: Normal sensory conduction in the nerves of the leg in man. J Neural NeuroSurg Psychiatry 1971;34:404-414.

7 Soudmand R, Charles Ward L, Swift TR: Effect of height on nerve conduction velocity. Neurology 1982;32:407-410.

8 Robinson LR, Rubner DE, Wahl PW, Fujimoto WY, Stolor WC: Influences of height and gender on normal nerve conduction studies. Arch Phys Med Rehabil 1993;74: 1134-1138.

9 Dorfman LJ, Robinson LR: Normative Data in Electrodiagnostic Medicine. AAEM Minimonograph No 47, January 1997.

10 Kimura J: Assessment of individual nerves; in Kimura $\mathbf{J}$ (ed): Electrodiagnosis in Diseases of Nerve and Muscle: Principles and Practice, ed 2. Philadelphia, Davis, 1989, pp 103-139.
11 Shehab D: Normative data of nerve conduction studies in the upper limb in Kuwait: Are they different from the Western data? Med Principles Pract 1998;7:203-208.

12 Robinson KR, Temkin NR, Fujimoto WY, Stolov WC: Impact of statistical methodology on normal limits in nerve conduction studies. Muscle Nerve 1991;14:1084-1090.

13 Lee HJ, Bach JR, Delisa JA: Peroneal motor conduction to the proximal muscles: Alternative approach to conventional methods. Am J Phys Med Rehabil 1997;76:197199.

14 Trojaborg WT, Moon A, Anderson BB, Trojaborg N: Sural nerve conduction parameters in normal subjects related to age, gender, temperature and height: A reappraisal. Muscle Nerve 1992;15:666-671. 